\title{
Molecular identification of Trypanosoma brucei gambiense in naturally infected pigs, dogs and small ruminants confirms domestic animals as potential reservoirs for sleeping sickness in Chad
}

Joël Vourchakbé, Zebaze Arnol Auvaker Tiofack ${ }^{1}$, Tagueu Sartrien Kante ${ }^{1}$, Mbida Mpoame ${ }^{3}$, and Gustave Simo ${ }^{1, *}$

${ }^{1}$ Molecular Parasitology and Entomology Unit, Department of Biochemistry, Faculty of Science, University of Dschang, PO Box 67 Dschang, Cameroon

${ }^{2}$ Department of Chemistry-Biology-Geology, Faculty of Science and Technology, University of Doba, PO Box 03 Doba, Chad

${ }^{3}$ Laboratory of Applied Biology and Ecology (LABEA), Department of Animal Biology, Faculty of Science, University of Dschang, PO Box 067 Dschang, Cameroon

Received 19 July 2020, Accepted 2 November 2020, Published online 18 November 2020

\begin{abstract}
Human African trypanosomiasis (HAT) has been targeted for zero transmission to humans by 2030. Animal reservoirs of gambiense-HAT could jeopardize these elimination goals. This study was undertaken to identify potential host reservoirs for Trypanosoma brucei gambiense by detecting its natural infections in domestic animals of Chadian HAT foci. Blood samples were collected from 267 goats, 181 sheep, 154 dogs, and 67 pigs. Rapid diagnostic test (RDT) and capillary tube centrifugation (CTC) were performed to search for trypanosomes. DNA was extracted from the buffy coat, and trypanosomes of the subgenus Trypanozoon as well as $T$. $b$. gambiense were identified by PCR. Of 669 blood samples, $19.4 \%$ were positive by RDT and $9.0 \%$ by CTC. PCR revealed 150 animals $(22.4 \%)$ with trypanosomes belonging to Trypanozoon, including 18 (12\%) T. b. gambiense. This trypanosome was found in all investigated animal species and all HAT foci. Between animal species or villages, no significant differences were observed in the number of animals harboring T. $b$. gambiense DNA. Pigs, dogs, sheep and goats appeared to be potential reservoir hosts for T. b. gambiense in Chad. The identification of T. b. gambiense in all animal species of all HAT foci suggests that these animals should be considered when designing new control strategies for sustainable elimination of HAT. Investigations aiming to decrypt their specific role in each epidemiological setting are important to achieve zero transmission of HAT.
\end{abstract}

Key words: Animal reservoir, Trypanosoma brucei gambiense, Sleeping sickness, Domestic animals.

Résumé - L'identification moléculaire de Trypanosoma brucei gambiense chez les porcs, les chiens et les petits ruminants naturellement infectés confirme les animaux domestiques comme réservoirs potentiels de la maladie du sommeil au Tchad. La trypanosomiase humaine africaine (THA) a été ciblée pour une interruption de sa transmission en 2030. Le réservoir animal de la THA à Trypanosoma brucei gambiense pourrait compromettre ces objectifs d'élimination. Cette étude a été entreprise pour identifier des potentiels hôtes réservoirs de Trypanosoma brucei gambiense en détectant ses infections naturelles chez des animaux domestiques des foyers tchadiens de la THA. Des échantillons de sang ont été prélevés chez 267 chèvres, 181 moutons, 154 chiens et 67 porcs. Le test de diagnostic rapide (TDR) et la centrifugation en tube capillaire (CTC) ont été utilisés pour mettre en évidence les trypanosomes. L'ADN a été extrait des couches leucocytaires et les trypanosomes du sous-genre Trypanozoon ainsi que T. $b$. gambiense ont été identifiés par PCR. Sur les 669 échantillons de sang analysés, 19,4\% étaient positifs au TDR et $9,0 \%$ à la CTC. La PCR a révélé $150(22,4 \%)$ animaux avec des trypanosomes du sous-genre Trypanozoon donc 18 (12\%) portant l'ADN de T. b. gambiense. Ce dernier a été identifié chez toutes les espèces animales de tous les foyers de la THA. Entre les espèces animales ou les villages, aucune différence significative n'a été observée entre le nombre d'animaux ayant l'ADN de T. b. gambiense. Les porcs, les chiens, les moutons et les chèvres sont apparus comme des hôtes réservoirs potentiels de $T$. $b$. gambiense au Tchad. L'identification de $T$. $b$. gambiense, chez toutes les espèces animales étudiées dans tous les foyers, suggère de considérer ces animaux dans la conception des nouvelles stratégies de lutte visant une élimination durable de la THA. Des investigations visant à décrypter leur rôle spécifique dans chaque contexte épidémiologique sont nécessaires pour parvenir à une transmission nulle de la THA.

*Corresponding author: gsimoca@yahoo.fr; gustave.simo@univ-dschang.org 


\section{Introduction}

Human African trypanosomiasis (HAT) also known as sleeping sickness is a neglected tropical disease that affects mostly rural populations of sub-Saharan African countries. Transmitted by an arthropod vector of the genus Glossina, this infectious disease is caused by protozoan parasites of the Trypanosoma brucei species complex which include Trypanosoma brucei brucei, Trypanosoma brucei gambiense, and Trypanosoma brucei rhodesiense. While T. b. brucei infects domestic and wild animals and induces animal African trypanosomiasis, it is non-infective to humans. The other two subspecies are infective to humans and cause HAT. Trypanosoma $b$. gambiense is responsible for the chronic or gambiense form of HAT that occurs in West and Central Africa. This form accounts for about $98 \%$ of all current HAT diagnosed cases [59]. The acute form of HAT accounts for the remaining $2 \%$ of diagnosed cases. Found in Eastern and Southern Africa, this acute form is caused by $T$. $b$. rhodesiense [59]. During the last few decades, control efforts based on case detection and treatment, sometimes coupled with vector control, made it possible to considerably reduce the incidence of HAT and brought this disease under control with fewer than 2000 cases reported in 2017 [59]. With this success, gambienseHAT has been included in the World Health Organization (WHO) road map that targets its sustainable elimination or interruption of transmission (zero transmission) to humans for $2030[6,14,59]$. Achieving these goals requires strengthening of current control activities and identifying components that could jeopardize this sustainable elimination, and that have not been considered in the design of current control measures. It is in this framework that concerns about the epidemiological importance of animal reservoirs have been raised for several decades [11, 36, 57], and recently during the third WHO stakeholders meeting on gambiense-HAT elimination that took place in Geneva in April 2018 [59]. Understanding the significance of animal reservoirs in the maintenance of the transmission and reemergence of gambiense-HAT therefore requires further attention.

Gambiense-HAT has generally been considered an anthroponotic disease and consequently, its control program was mainly focused on stopping its transmission by treating human cases and eliminating the tsetse vector [6]. However, animal reservoirs have been reported to be one of the epidemiological components that could play an important role in the endemic nature of HAT, and also for its resurgence in the historic foci of West and Central Africa [6, 41]. Previous investigations revealed several domestic and wild animal species as potential hosts of T. b. gambiense in West and Central African HAT foci $[8,9,16,17,28,40-42,44,50,51]$. For instance, natural infections of T. $b$. gambiense have been reported in sheep and goats in Cameroon, Equatorial Guinea and Congo [8, 41, 44, 50], in pigs in Cameroon and Liberia [16, 42, 51], and in dogs in Liberia and Nigeria $[16,56]$. Besides these domestic species, several wild animal species have been also reported with natural infections of T. b. gambiense in Central African HAT foci [10, 17, 40]. In addition to these natural infections, experimental investigations have demonstrated the infectivity and transmissibility of T. b. gambiense to several of these animal species. All these data provide evidence of the presence of an animal reservoir that may threaten gambiense-HAT elimination. Although the epidemiological role of animals found with T. b. gambiense infections has not been deeply investigated in different epidemiological settings, these animals could act as reservoir hosts of $T$. b. gambiense and could maintain and/or ensure its transmission. However, the variability of the fauna composition and the nutritional behavior of tsetse flies in different HAT foci suggest that the epidemiological significance of any animal reservoir may vary according to the specific ecosystems of each HAT focus. Understanding the real epidemiological situation of the disease in each focus is becoming of great importance, especially in some HAT foci of West and Central Africa where elimination could be foreseen.

Chad is among the countries reporting 10 to 100 new cases per year. In Chadian HAT foci, a significant decrease was observed with a $78 \%$ reduction in reported cases between 2016 and 2018 [15]. The maintenance of an adequate level of control activities with the implementation of a vector control program in 2014 has greatly reduced the tsetse population in some HAT foci like that of Mandoul [27]. Moreover, only 12 new HAT cases were reported in Chadian HAT foci in 2018 [15]. Although Chad is not yet eligible for validation of gambiense HAT elimination as a public health problem at the national level, the low number of new HAT cases highlights progress towards the elimination target. In this context, factors such as animal reservoirs, reported as one of the components that could jeopardize this elimination, must be investigated to identify potential vertebrate hosts for $T$. $b$. gambiense. In Chadian HAT foci where no investigation on animal reservoirs of gambiense-HAT has been undertaken, the epidemiological role of different animal species in the transmission and maintenance of $T$. b. gambiense remains unknown.

The present study aims to generate data on animal reservoirs of gambiense-HAT by identifying natural infections of T. b. gambiense in domestic animals of HAT foci of Chad.

\section{Materials and methods \\ Ethical considerations}

This study was approved by the Bioethics Committee of the Ministry of High Education, Research and Innovation of Chad by decree number 462/PR/PM/MESRI/SG/CNBT/2017. In addition to this approval, the review board of the molecular parasitology and entomology unit of the Department of Biochemistry of the Faculty of Science of the University of Dschang gave its agreement. The local administration, as well as the religious and traditional authorities of each HAT focus also gave their approval after detailed explanation of the objectives of the study. Verbal consent was obtained from animal owners after the aim of the study had been explained to each of them.

\section{Sampling sites}

This cross-sectional study was performed from February 2018 to June 2019 in three HAT foci of the extreme south of Chad. These foci include the Mandoul, Maro and Moissala HAT foci [58]. 
- The HAT focus of Mandoul $\left(8^{\circ} 6^{\prime} 57^{\prime \prime} \mathrm{N} ; 17^{\circ} 06^{\prime} 58^{\prime \prime} \mathrm{E}\right)$ is located $50 \mathrm{~km}$ from Doba, which is the capital of Logone Oriental region. At the borders of Cameroon and the Central African Republic, this HAT focus belongs to areas showing low and very low risk of $T . \quad b$. gambiense infections [15, 46]. It covers 41 villages with an estimated population of 13,799 inhabitants. Its temperature varies from 22 to $38{ }^{\circ} \mathrm{C}$, and the average annual rainfall is $1000 \mathrm{~mm}$ [26]. The landscape is dominated by forest galleries and wooded savannahs. In this HAT focus, domestic animals were sampled in 41 villages (Table S1).

- The HAT focus of Maro $\left(8^{\circ} 28^{\prime} 33^{\prime \prime} \mathrm{N} ; 18^{\circ} 46^{\prime} 10^{\prime \prime} \mathrm{E}\right)$ is located $55 \mathrm{~km}$ from Sarh, the capital of the Moyen-Chari region. It is at the border of the Central African Republic and covers about 33 villages for an estimated population of 8526 inhabitants. It belongs to HAT foci showing moderate risk of $T . b$. gambiense infections [15]. In this focus, the temperature varies from 25 to $38^{\circ} \mathrm{C}$ and the precipitation from $800 \mathrm{~mm}$ to $1300 \mathrm{~mm}$. The vegetation is formed by savannah and clear forests dotted with trees. For this study, animals were sampled in 31 villages.

- The HAT focus of Moïssala $\left(8^{\circ} 20^{\prime} 25^{\prime \prime} \mathrm{N} ; 1^{\circ} 45^{\prime} 58^{\prime \prime} \mathrm{E}\right)$ is part of the great historical HAT focus of Middle Chari [3]. It extends along the network dominated by the Nana-Barya river, between the Bahr Sara (Ouham) and Chari rivers. Located in the South of Koumra, the Capital of the Mandoul region, about $400 \mathrm{~km}$ from the Central Africa Republic border, the Moissala focus belongs to HAT foci showing moderate risk of $T$. b. gambiense infections [14, 15]. Its population is estimated to be 12,234 inhabitants distributed in 41 villages. In this HAT focus, the temperature varies from 24 and $38{ }^{\circ} \mathrm{C}$ with an average annual rainfall of about $1100 \mathrm{~mm}$. The vegetation is dominated by forest galleries. Domestic animals of 42 villages were sampled.

Inhabitants of these three Chadian HAT foci are mainly traditional smallholder farmers. The main crops are cotton, millet and sesame. Inhabitants also practice fishing, gathering, hunting, extensive breeding of cattle, and small-scale breeding of sheep, goats, pigs, and equines that are generally used for transport and traction. These different animal species move in and around biotopes that are favorable to tsetse flies and, consequently, are exposed to tsetse bites, like humans.

\section{Sample collection}

Domestic animals including pigs, dogs, sheep and goats were sampled during three field surveys performed in villages of each of the three HAT foci of Chad. The sampling was done in all villages where at least one HAT case was reported during the last decade, as well as in some neighboring villages. These villages were selected on the basis of (i) their proximities with villages where an HAT case has been reported; (ii) the presence of different domestic animal species; and (iii) the presence of favorable biotopes for tsetse flies and trypanosome transmission. The first survey was performed from 7 to
27 March 2018 in the HAT focus of Maro, the second from 2 April to 12 May 2018 in the Mandoul HAT focus, and the last survey from 25 May to 14 June 2019 in the Moissala HAT focus. Before each survey, the objective of the study was explained for the second time to inhabitants and local authorities of each HAT focus. One day before each sampling, inhabitants of each village were asked to restrain and/or tie their animals around their houses. In each village, only animals that may have been exposed to trypanosome infections or tsetse bites by spending at least 3 months in the study zone were selected. For animal owners having fewer than three animals, all their animals were sampled, while for those having more than three animals satisfying the previous criterion, only three animals were randomly selected. With the cooperation of owners, about $5 \mathrm{~mL}$ of blood were collected from each domestic animal. Each collection was done into EDTA coated tubes. The blood collection was performed from the jugular vein in goats and sheep while in pigs and dogs, it was performed from the sub-clavicular and cephalic vein, respectively. In some dogs, blood samples were not collected due to their aggressiveness. Each blood tube was labelled and carefully packed. All dogs sampled in the three HAT foci were of local breed, originating from a mixture of different breeds. The pigs were Iberian pigs, "Landschwein pigs" and a mixture of different breeds. The sheep were "south sheep" made up of sheep of "Kirdi" or "Kirdimi" type and sheep of Mayo-Kebbi [12]. The goats were also "south goat" or "Kirdimi goat" or Guinean goats with djallonke and dwarf kirdi African goat breeds [12]. The goats and sheep breed sampled in this study have been reported to be able to control trypanosome infections [39].

\section{Immunologic test and parasitological examination}

The immunologic test or gambiense-HAT rapid diagnostic test (RDT) was performed to identify animals that would have been in contact with $T$. $b$. gambiense. The RDT named SD BIOLINE HAT was the test used in this study. Developed using native variable surface glycoproteins (VSGs) (Nat-LiTat 1.3 and Nat-LiTat 1.5) obtained from the Institute of Tropical Medicine (ITM) of Belgium [29], this test detects anti-VSG LiTat 1.3 and anti-VSG LiTat 1.5 antibodies [2, 21, 55]. This RDT was performed as described by Matovu et al. [29].

The capillary tube centrifugation test (CTC) was performed on each blood sample to search for trypanosomes. This was performed as described by Woo [60]. All animals found with trypanosome infections through the CTC were treated. Infected goats, sheep and dogs were treated with $0.5 \mathrm{mg}$ of Trypamidium per $1 \mathrm{~kg}$ body weight, while pigs were treated with $0.5 \mathrm{mg}$ of Quinapyramine per $1 \mathrm{~kg}$ body weight following local veterinarian's advice.

The blood samples remaining in EDTA coated tubes were centrifuged at 13,000 rpm for $5 \mathrm{~min}$. After centrifugation, the buffy coat was removed from each tube and transferred to microtubes of $1.5 \mathrm{~mL}$ that were stored into an electric cooler. These buffy coat samples were transported to the molecular parasitology and entomology unit of the Faculty of Science of the University of Dschang in Cameroon. They were transported in 
an electric cooler and once at the laboratory, they were subsequently stored at $-20{ }^{\circ} \mathrm{C}$ until DNA extraction for molecular analyses.

\section{DNA extraction}

DNA was extracted from each buffy coat using the cethyl trimethyl ammonium bromide (CTAB) method. In each microtube of $2 \mathrm{~mL}, 500 \mu \mathrm{L}$ of buffy coat were mixed with $1 \mathrm{~mL}$ of nuclease-free water. After vigorous homogenization of each microtube, the mixture was centrifuged at $11,000 \mathrm{rpm}$ for $15 \mathrm{~min}$. The supernatant was removed and $600 \mu \mathrm{L}$ of CTAB buffer (CTAB at 5\%; $1 \mathrm{M}$ Tris, $\mathrm{pH} 8$; $0.5 \mathrm{M}$ EDTA, pH 8; $5 \mathrm{M} \mathrm{NaCl}$ ) were added to the pellet that was re-suspended and incubated in a water bath at $60{ }^{\circ} \mathrm{C}$ for $30 \mathrm{~min}$. Thereafter, $600 \mu \mathrm{L}$ of chloroform/isoamyl alcohol (24/1) mixture were added to the resulting pellet of each microtube. This mixture was slowly homogenized for $15 \mathrm{~min}$ and then centrifuged at $13,000 \mathrm{rpm}$ for $15 \mathrm{~min}$. The upper aqueous phase was removed and transferred to another microtube of $1.5 \mathrm{~mL}$. DNA was precipitated by addition of $600 \mu \mathrm{L}$ of isopropanol. After gentle homogenization of each microtube for $5 \mathrm{~min}$ and its incubation overnight at $-20{ }^{\circ} \mathrm{C}$, each microtube was centrifuged at $13,000 \mathrm{rpm}$ for $15 \mathrm{~min}$. DNA pellet was subsequently washed twice with cold $70 \%$ ethanol and dried overnight at room temperature. The resulting DNA pellet was re-suspended in $50 \mu \mathrm{L}$ of sterile nuclease free water and subsequently stored at $-20^{\circ} \mathrm{C}$ until use.

\section{Molecular identification of trypanosomes of the subgenus Trypanozoon}

Molecular identification was done as described by Simo et al. [51] using TBR-1/2 primers that are specific to trypanosomes of the subgenus Trypanozoon [38]. PCR reactions were performed in a final volume of $25 \mu \mathrm{L}$ containing $5 \mathrm{~mL}$ of DNA extracts as template, $1 \times$ PCR buffer $(10 \mathrm{mM}$ Tris$\mathrm{HCl}$ ( $\mathrm{pH}$ 9), $50 \mathrm{mM} \mathrm{KCl}), 2 \mathrm{mM} \mathrm{MgCl} 2,20$ picomoles of each primer (TBR-1: 5'-GAATATTAAACAATGCGCAG-3'; TBR-2: 5'-CCATTTATTAGCTTTGTTGC-3'), $100 \mathrm{mM}$ of each dNTP and 1 unit of Taq DNA polymerase. The amplification program contained one cycle of denaturation at $94{ }^{\circ} \mathrm{C}$ for 5 min followed by 40 amplification cycles. Each of these cycles was made up of a denaturation step at $94{ }^{\circ} \mathrm{C}$ for $30 \mathrm{~s}$, an annealing step at $55{ }^{\circ} \mathrm{C}$ for $30 \mathrm{~s}$, and an extension step at $72{ }^{\circ} \mathrm{C}$ for $1 \mathrm{~min}$. This was followed by a final extension at $72{ }^{\circ} \mathrm{C}$ for $10 \mathrm{~min}$.

The amplified products were separated by electrophoresis on $1.5 \%$ agarose gel that was subsequently stained with ethidium bromide and visualized under UV light. A sample was considered positive for trypanosomes of the subgenus Trypanozoon if a DNA fragment of about $177 \mathrm{bp}$ was observed after amplification with TBR-1/2 primers. In addition to this DNA fragment of $177 \mathrm{bp}$, other DNA fragments can be observed because the target fragment is a satellite DNA sequence with repetitions of different sizes. For subsequent analyses, all samples that were positive for trypanosomes of the subgenus Trypanozoon were selected.

\section{Molecular identification of $T$. b. gambiense}

Searching for T. b. gambiense was performed on all samples that have shown a DNA fragment of about 177 bp corresponding to the size expected for trypanosomes of the subgenus Trypanozoon (T. b. brucei, T. evansi, T. b. gambiense, T. b. rhodesiense or $T$. equiperdum). The molecular identification of $T$. b. gambiense was done using two PCR rounds as described by Cordon-Obras et al. [8]. During this identification, two pairs of specific primers for $T$. $b$. gambiense were used: TgSGP-1/2 (TgSGP-1: 5'-GCT GCT GTG TTC GGA GAG C-3'; TgSGP-2: 5'-GCC ATC GTG CTT GCC GCT C-3') described by Radwanska et al. [47] and TgsGP-a/as (TgsGPs: 5'-TCA GAC AGG GCT GTA ATA GCA AGC-3'; TgsGP-as: 5'-GGG CTC CTG CCT CAA TTG CTG CA-3') designed by Morrison et al. [37].

The first PCR round was carried out in a total volume of $25 \mu \mathrm{L}$ containing $1 \times$ PCR buffer (Tris $-10 \mathrm{mM} \mathrm{HCl}(\mathrm{pH}$ 9.0), $50 \mathrm{mM} \mathrm{KCl}, 3 \mathrm{mM} \mathrm{MgCl} 2$ ), 15 picomoles of each primer (TgSGP-1/2), $100 \mathrm{mM}$ of each dNTP, one unit of Taq DNA polymerase, $5 \mu \mathrm{L}$ of DNA extract and $14 \mu \mathrm{L}$ of sterile water. The amplification program contained an initial denaturation step at $95{ }^{\circ} \mathrm{C}$ for $3 \mathrm{~min}$. This was followed by 45 cycles made up of a denaturation step at $95^{\circ} \mathrm{C}$ for $30 \mathrm{~s}$, an annealing step at $63{ }^{\circ} \mathrm{C}$ for $1 \mathrm{~min}$ and an elongation step at $72{ }^{\circ} \mathrm{C}$ for $1 \mathrm{~min}$. A final elongation was done at $72{ }^{\circ} \mathrm{C}$ for $5 \mathrm{~min}$. Amplicons of the first PCR were diluted 10 times and $5 \mu \mathrm{L}$ of each dilution were subsequently used as DNA template for the second PCR in which TgsGP-s/as primers were used. In this nested PCR, only 25 amplification cycles were performed in the same conditions as for the first PCR.

Amplicons from the second PCR were resolved by electrophoresis on $2 \%$ agarose gel containing ethidium bromide $(0.3 \mu \mathrm{g} / \mathrm{mL})$. DNA bands were subsequently visualized and then photographed under UV light. All samples in which a DNA fragment of about $270 \mathrm{bp}$ was revealed after PCR and electrophoresis were considered positive for T. b. gambiense.

\section{Data analyses}

The infection rates of trypanosomes of the subgenus Trypanozoon and those of T. b. gambiense were compared between animal species and HAT foci. These comparisons were performed using XLSTAT 2016 software. The chi-squared test $\left(\chi^{2}\right)$ was used to compare the infection rates between animal species and different HAT foci. The difference was considered significant if the $p$-value was below 0.05 .

\section{Results}

The 669 domestic animals analyzed in this study were sampled in 113 villages: 41, 31 and 41 villages of the Mandoul, the Maro and the Moissala HAT foci, respectively (Table S1). These 669 animals include 267 goats (39.9\%), 181 sheep (27.1\%), 154 dogs $(23.0 \%)$, and 67 pigs (10.0\%) (Table 1). Of these 669 animals, 268 (40.1\%), 232 (34.7\%) and 169 (25.3\%) were sampled in the HAT foci of Mandoul, Maro and Moissala, respectively (Table 2). Details regarding the 
Table 1. Trypanosome infections according to animal species.

\begin{tabular}{|c|c|c|c|c|c|}
\hline \multirow[t]{2}{*}{ Animal species } & \multirow[t]{2}{*}{$\mathrm{NE}$} & \multirow[t]{2}{*}{$\mathrm{RDT}+(\%)$} & \multirow[t]{2}{*}{$\mathrm{T}+(\%)$} & \multicolumn{2}{|c|}{ PCR results } \\
\hline & & & & $\mathrm{TB}+(\%)$ & $\mathrm{TBG}+(\%)$ \\
\hline Goat & 267 & $53(19.8)$ & $28(10.4)$ & $66(24.7)$ & $8(3.0)$ \\
\hline Sheep & 181 & $37(20.4)$ & $13(7.2)$ & $44(24.3)$ & $5(2.8)$ \\
\hline Dog & 154 & $29(18.8)$ & $13(8.4)$ & $32(20.8)$ & $4(2.6)$ \\
\hline Pig & 67 & $11(16.4)$ & $6(8.9)$ & $8(11.9)$ & $1(1.5)$ \\
\hline Total & 669 & $130(19.4)$ & $60(9.0)$ & $150(22.4)$ & $18(2.7)$ \\
\hline$\chi^{2}$ & - & 2.09 & 1.51 & 5.65 & 1.03 \\
\hline$p$-value & - & 0.91 & 0.68 & 0.13 & 0.96 \\
\hline
\end{tabular}

NE: Number of animals examined; RDT: Rapid diagnosis test; T+: trypanosome infections revealed by capillary tube centrifugation; TB+: trypanosomes of the subgenus Trypanozoon: TBG: Trypanosoma brucei gambiense.

Table 2. Trypanosome infections according to HAT foci.

\begin{tabular}{|c|c|c|c|c|c|c|}
\hline \multirow[t]{2}{*}{ HAT foci } & \multirow[t]{2}{*}{ Villages } & \multirow[t]{2}{*}{$\mathrm{NE}$} & \multirow[t]{2}{*}{$\mathrm{RDT}+(\%)$} & \multirow[t]{2}{*}{$\mathrm{T}+(\%)$} & \multicolumn{2}{|c|}{ PCR results } \\
\hline & & & & & $\mathrm{TB}+(\%)$ & $\mathrm{TBG}+(\%)$ \\
\hline Mandoul & 41 & 268 & $51(19.0)$ & $20(7.5)$ & $43(16.0)$ & $12(4.5)$ \\
\hline Maro & 31 & 232 & $44(19.0)$ & $22(9.5)$ & $51(22.0)$ & $4(1.7)$ \\
\hline Moissala & 41 & 169 & $35(20.7)$ & $18(10.7)$ & $56(33.1)$ & $2(1.2)$ \\
\hline Total & 113 & 669 & $130(19.4)$ & $60(9.0)$ & $150(22.4)$ & $18(2.7)$ \\
\hline$\chi^{2}$ & - & - & 3.23 & 1.41 & 17.44 & 5.39 \\
\hline$p$-value & - & - & 0.52 & 0.50 & 0.0001 & 0.07 \\
\hline
\end{tabular}

HAT: Human African Trypanosomiasis; NE: Number of animals examined; RDT: Rapid diagnosis test; T+: trypanosome infections revealed by capillary tube centrifugation; TB+: trypanosomes of the subgenus Trypanozoon: TBG: Trypanosoma brucei gambiense.

distribution of domestic animals according to villages of each HAT focus are reported in Table S1.

\section{Serology}

The RDT was positive in 130 animals (19.4\%): 53 goats (19.8\%), 37 sheep (20.4\%), 29 dogs (18.8\%), and 11 pigs (16.4\%). The positivity rate of RDT varied within and between HAT foci (Table S1). Comparing the positivity rates of RDT, no statistically significant difference $\left(\chi^{2}=2.09 ; p=0.91\right)$ was observed between different animal species (Table 1). Although the positivity rates in RDT varied slightly between HAT foci, no significant difference $\left(\chi^{2}=3.23 ; p=0.52\right)$ was observed (Table 2).

\section{Parasitology}

The CTC test revealed 60 (9.0\%) animals with trypanosome infections. At this stage, the specific identification of trypanosomes was not possible. All four domestic animal species were found with trypanosome infections at all the study sites (Tables 1 and 2). The proportion of infected animals was highest in goats $(10.4 \%)$ followed by pigs $(8.9 \%)$. The lowest infection rate of $7.2 \%(13 / 181)$ was observed in sheep (Table 1). However, these differences in infection rates between animal species were not statistically significant $\left(\chi^{2}=1.51 ; p=0.68\right)$ (Table 1).

Of the 60 animals in which trypanosome infections were revealed by CTC, 22 (9.5\%), 20 (7.5\%), and 18 (10.7\%) were from the HAT foci of Maro, Mandoul and Moissala, respectively (Table 2). Between these HAT foci, no significant difference $\left(\chi^{2}=1.14 ; p=0.50\right)$ was observed in the trypanosome infection rates revealed by CTC (Table 2).

\section{Molecular analyses}

\section{Molecular identification of trypanosomes of the subgenus Trypanozoon}

From the 669 animals analyzed in this study, the specific PCR targeting a multi-copy 177 bp repeat sequence of trypanosomes of the subgenus Trypanozoon revealed this sequence in 150 animals (22.4\%). Sixty six goats (24.6\%), 44 sheep $(24.30 \%), 32$ dogs $(20.8 \%)$, and 8 pigs (11.9\%) were tested positive for trypanosomes of the subgenus Trypanozoon. Despite some small differences observed in these trypanosome infection rates, no significant difference $\left(\chi^{2}=5.65 ; p=0.13\right)$ was found between animal species.

Of the 150 animals found with trypanosomes of the subgenus Trypanozoon, $56(33.1 \%)$ were from the Moissala HAT focus, 51 (22.0\%) from Maro, and 43 (16.0\%) from Mandoul. The highest infection rate of $33.1 \%$ (56/169) was observed in animals of the HAT focus of Moissala, while the lowest rate of $16.0 \%$ was observed in those of the Mandoul HAT focus (Table 2). Infections due to trypanosomes of the subgenus Trypanozoon were widely distributed in animals of different villages of the three HAT foci (Figs. 2-4). The difference between the trypanosome infection rates revealed by PCR 


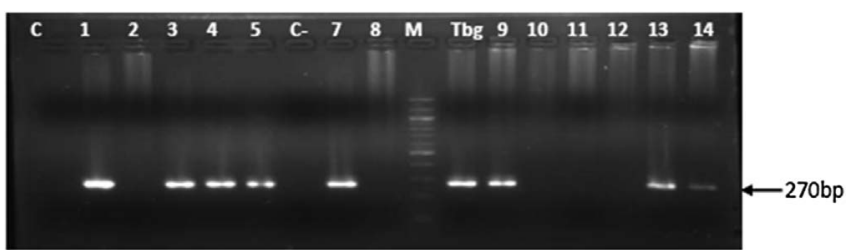

Figure 1. Photo of agarose gel showing specific DNA fragments of T. b. gambiense that were amplified from domestic animals. $\mathrm{C}-$ : Negative control, Tbg: Positive control made of purified DNA from T. b. gambiense human isolate; M: Molecular marker (100 bp ladder); 1, 3, 4, 5, 7, 9, 13 and 14: samples with T. b. gambiense infections; 2, 8, 10, 11 and 12: samples without $T$. b. gambiense infection, but harboring other trypanosomes of the subgenus Trypanozoon.

in the three HAT foci was statistically significant $\left(\chi^{2}=17.44\right.$; $p=0.0001)$ (Table 2).

Fifty seven out of the 150 animals (38.0\%) that were positive for PCR targeting trypanosomes of the subgenus Trypanozoon were tested positive for trypanosome infection by CTC. Three out of the 60 animals that were positive in CTC were tested negative in the PCR targeting trypanosomes of the subgenus Trypanozoon.

\section{Molecular identification of $T$. b. gambiense infections}

Of the 150 animals tested positive for trypanosomes of the subgenus Trypanozoon by the first PCR, 18 (12.0\%) of them were found with $T$. $b$. gambiense infections as shown by the amplification of specific DNA fragments of $270 \mathrm{bp}$ of this trypanosome subspecies (Fig. 1). All four animal species investigated in this study were found with $T . \quad b$. gambiense infections (Table 1). Of the 18 animals found with T. b. gambiense infections, 8 (44.4\%), 5 (27.8\%), 4 (22.2\%) and $1(5.6 \%)$ were from goats, sheep, dogs and pigs, respectively. The overall $T$. $b$. gambiense infection rate was $2.7 \%$ $(18 / 669)$. The highest infection rate of $3.0 \%(8 / 268)$ was found in goats, followed by sheep (2.8\%), dogs $(2.6 \%)$, and pigs $(1.5 \%)$ (Table 1). Comparing the infection rates of T. b. gambiense, no significant difference $\left(\chi^{2}=1.03 ; p=0.96\right)$ was observed between animal species (Table 1). Of the 60 animals revealed with trypanosome infections by CTC, the PCR targeting T. b. gambiense detected this trypanosome subspecies in $10(16.7 \%)$ of them. Eight animals with DNA of T. b. gambiense and selected by PCR targeting trypanosomes of the subgenus Trypanozoon were negative to the parasitological test (CTC).

Animals with $T . b$. gambiense infections were identified in each HAT focus investigated in this study. Of the 18 animals tested positive for T. b. gambiense infections, 12 (66.7\%) were from the HAT focus of Mandoul (Fig. 2), while 4 (22.2\%) and $2(11.1 \%)$ were from the Maro (Fig. 3) and Moissala (Fig. 4) HAT foci, respectively. In all villages that have reported T. b. gambiense infections in humans, domestic animals were also found with human infective trypanosome (Figs. 2-4). However, in two and five villages of the HAT foci of Maro and Mandoul, respectively where no HAT case was reported, animals were found with $T$. b. gambiense infections. The

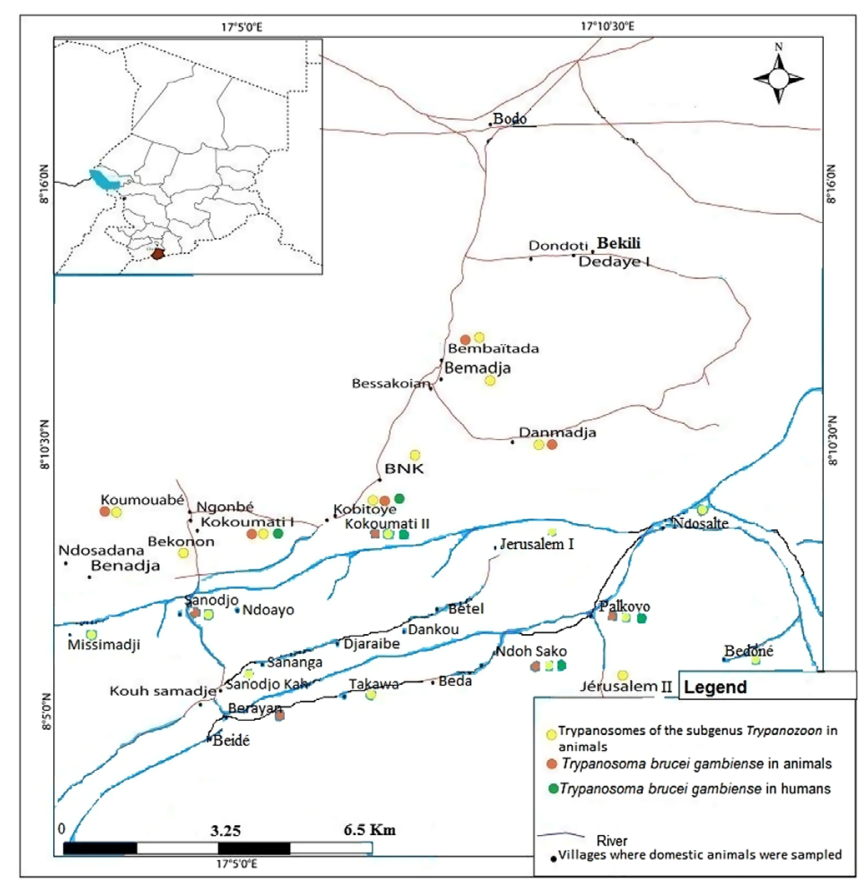

Figure 2. Distribution of trypanosome infections in humans and animals of the sleeping sickness focus of Mandoul. Green dots represent villages where HAT cases have been reported by the national sleeping sickness control program of Chad; yellow dots represent villages where animals were found with trypanosomes of the subgenus Trypanozoon; orange dots represent villages where animals were found with $T$. $b$. gambiense infections.

overall highest infection rate of $T . b$. gambiense of $4.5 \%$ was reported in animals of the HAT focus of Mandoul. This was followed by $1.7 \%$ and $1.2 \%$ in the HAT foci of Maro and Moissala, respectively. Between these HAT foci, no significant difference $\left(\chi^{2}=5.39 ; p=0.07\right)$ was observed in the overall infection rates of T. b. gambiense (Table 2).

\section{Distribution of trypanosome infections between villages and foci}

Amongst the 113 villages where the sampling was undertaken, animals were tested positive for T. $b$. gambiense in 16 of them (11.3\%): 2 villages of the Moissala HAT focus, 4 of Maro, and 10 of Mandoul. Two animals from Kokoumati I and two others from Kobitoye, all of the Mandoul HAT focus, were positive for $T$. $b$. gambiense. Trypanosomes of the subgenus Trypanozoon were found in animals from 56 villages: 20, 15 and 21 villages of the HAT foci of Mandoul, Maro and Moissala, respectively (Table S1). Of these 56 villages, animals with $T . b$. gambiense infections were reported in 16 of them: 10 villages of the Mandoul HAT focus, 4 of Maro, and 2 of Moissala (Table S1). Fifty seven villages including 21, 16 and 20 villages of the HAT foci of Mandoul, Maro and Moissala, respectively reported no animal with trypanosomes of the subgenus Trypanozoon. The difference in the number of villages reporting animals with trypanosomes of the subgenus Trypanozoon was not statistically significant $\left(\chi^{2}=1.66 ; p=0.44\right)$ between HAT foci. For villages reporting 


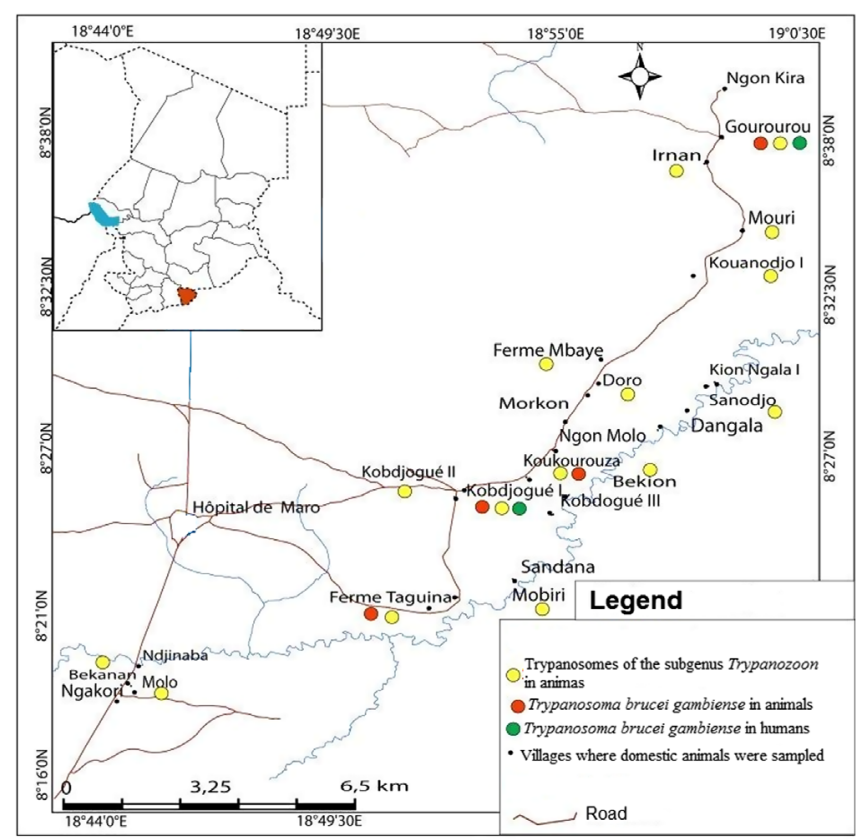

Figure 3. Distribution of trypanosome infections in humans and animals of the sleeping sickness focus of Maro. Green dots represent villages where HAT cases have been reported by the national sleeping sickness control program of Chad; yellow dots represent villages where animals were found with trypanosomes of the subgenus Trypanozoon; orange dots represent villages where animals were found with $T$. $b$. gambiense infections.

animals with $T . b$. gambiense infections, a significant difference $\left(\chi^{2}=9.75 ; p=0.008\right)$ was observed between HAT foci. Between villages with and without HAT cases, there was no significant difference $\left(\chi^{2}=4.0 ; p=0.05\right.$ for the HAT focus of Moissala; $\chi^{2}=0.0 ; p=1$ for the HAT foci of Mandoual and Maro) in the number of animals that were positive for T. b. gambiense. Comparing the number of animals with T. b. gambiense infections in villages reporting both HAT cases and positive animals for $T$. $b$. gambiense, no significant difference $\left(\chi^{2}=3.0 ; p=0.22\right)$ was observed between HAT foci. For similar comparison between villages without HAT cases, but reporting positive animals for $T$. $b$. gambiense, a significant difference $\left(\chi^{2}=8.143 ; p=0.02\right)$ was observed.

Among the 16 villages reporting animals tested positive for T. b. gambiense, HAT cases were reported in $9(56.3 \%)$ of them. Of the 104 villages with no HAT case, animals positive for T. b. gambiense were reported in $7(6.7 \%)$ of them. No HAT case and no animal positive for $T$. $b$. gambiense were reported in $97(85.8 \%)$ villages. Moreover, no village reported HAT case and animals that were tested negative for T. b. gambiense. Considering villages reporting positive animals for $T$. $b$. gambiense, the difference between the numbers of villages with (9) and without (7) HAT case was not statistically significant $\left(\chi^{2}=0.48 ; p=0.49\right)$. For villages reporting no HAT case, a significant difference $\left(\chi^{2}=155.026 ; p<0.0001\right)$ was observed between the numbers of villages with (7) and without (97) positive animals for T. $b$. gambiense. Between the numbers of villages with (16) and without (97) animals positive for $T$. $b$. gambiense, a significant difference $\left(\chi^{2}=3.84 ; p<0.0001\right)$ was also observed.

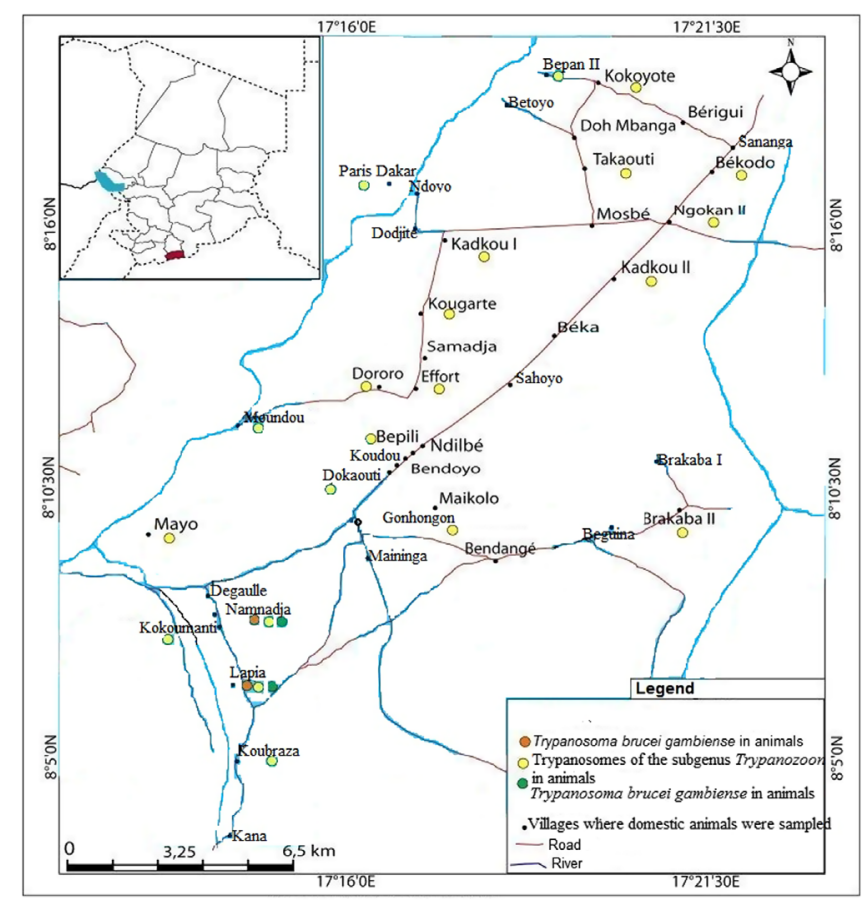

Figure 4. Distribution of trypanosome infections in humans and animals of the sleeping sickness focus of Moissala. Green dots represent villages where HAT cases have been reported by the national sleeping sickness control program of Chad; yellow dots represent villages where animals were found with trypanosomes of the subgenus Trypanozoon; orange dots represent villages where animals were found with $T$. b. gambiense infections.

\section{Comparison between RDT and PCR targeting T. b. gambiense and trypanosomes of the subgenus Trypanozoon}

RDT targeting antibodies against $T$. $b$. gambiense and PCR targeting trypanosomes of the subgenus Trypanozoon were simultaneously positive and negative for $57(8.5 \%)$ and 446 (66.7\%) animals, respectively. Moreover, RDT was positive in 73 animals $(10.9 \%)$ that were negative by PCR, while trypanosomes of the subgenus Trypanozoon were detected by PCR in 93 animals (13.9\%) negative to RDT.

For RDT targeting antibodies for $T$. $b$. gambiense and PCR targeting T. b. gambiense, 549 samples $(82.1 \%)$ revealed concordant results for the two tests, while discordant results were reported in 120 samples (17.9\%) (Table 3). Of the 549 samples with concordant results, 14 (2.6\%) and 535 (97.4\%) were positive and negative for both tests, respectively (Table 3).

Additional comparisons between RDT and PCR results were undertaken to see whether the performance of these tests could vary according to animal species. The data resulting from these comparisons are summarized in Table 3.

\section{Discussion}

To complete data generated on tsetse and T. $b$. gambiense infections in humans of most gambiense-HAT foci of West and Central Africa, natural infections of T. b. gambiense were investigated in domestic animals of three HAT foci of Chad. 
Table 3. Concordance and discordance between RDT and PCR targeting Trypanosoma brucei gambiense according to animal species.

\begin{tabular}{lcccc}
\hline Animal species & \multicolumn{2}{c}{ Concordance } & \multicolumn{2}{c}{ Discordance } \\
\cline { 2 - 3 } & RDT+/PCR_TBG+ & RDT-/PCR_TBG- & RDT+/PCR_TBG- & RDT-/PCR_TBG+ \\
\hline Goat & 6 & 212 & 47 & 2 \\
Sheep & 4 & 143 & 33 & 1 \\
Dog & 3 & 124 & 26 & 1 \\
Pig & 1 & 56 & 10 & 0 \\
Total & 14 & 535 & 116 & 4 \\
\hline
\end{tabular}

RDT: rapid diagnostic test; PCR: polymerase chain reaction; TBG: Trypanosoma brucei gambiense.

The gambiense-HAT RDT used in this study is an immunochromatographic test developed for the screening of gambiense-HAT. Expected to be positive when the host has been in contact with $T . b$. gambiense $[4,5]$, results of seroprevalence suggest that $19.4 \%$ of animals analyzed would have been in contact with T. b. gambiense. However, for the same samples, only $2.7 \%$ of animals were found with DNA of T. b. gambiense. Results of seroprevalence could be explained by the fact that a positive RDT could indicate current or past infections, while a positive PCR can be interpreted as an active infection although problems of reproducibility of PCR for diagnosis of HAT have been reported by Koffi et al. [24]. We cannot rule out the fact that some positive RDTs could result from crossreactions with epitopes of other trypanosome species [29]. In fact, sera from animals infected with either T. congolense, $T$. b. brucei or T. evansi have been shown to cross-react with antigens used in the RDT and the card agglutination test for gambiense human African trypanosomiasis [18, 43, 61]. Moreover, sera from both $T$. $b$. gambiense and $T$. $b$. rhodesiense patients have induced cross-reactions with a large number of trypanosome antigens including VSG LiTat 1.3 and VSG LiTat 1.5 [1]. The identification of $T$. congolense and $T$. vivax in equines of the same HAT foci [58] and the fact that three animals found with trypanosome infections by CTC, but in which trypanosomes of the subgenus Trypanozoon was not detected by PCR, suggest the presence of other trypanosome species in the study area. In addition, the high degree of similarity reported in the genomes of some trypanosomes highlights the probability of cross-reactions between antigens of different trypanosome species $[19,54]$. Our results are in agreement with the very few published data reporting the use of RDT on domestic animals $[28,58]$. They confirm the low specificity of RDT for the identification of $T . b$. gambiense in animals. This test is therefore not suitable for screening of T. b. gambiense in domestic livestock.

The infection rate of $22.4 \%$ revealed by PCR targeting trypanosomes of the subgenus Trypanozoon is higher than $9 \%$ obtained with CTC. Although the molecular tests have high sensitivity and excellent specificity in the detection of various trypanosomes species and subspecies, no single test is able to differentiate unequivocally trypanosomes of the sub genus Trypanozoon [7]. The animals found with trypanosomes of the subgenus Trypanozoon could be infected by $T$. evansi or T. equiperdum or T. b. brucei or T. $b$. gambiense or a mixture of some of them. Trypanosoma $b$. rhodesiense is not expected in this study because the Chadian HAT foci are located in a non-endemic area for the acute form of HAT. Remarkably, only
$16.7 \%$ of animals with trypanosome infections revealed by CTC were found with DNA of T. b. gambiense. These animals are probably carriers of significant parasite load that can be detected by parasitological tests. Nevertheless, it important to point out that some of these animals may harbor mixed infections of $T$. $b$. gambiense with other trypanosome species such as $T$. congolense, $T$. vivax or $T$. b. brucei that could induce significant parasite load [44]. Despite this parasite load, it is not possible to differentiate the infecting trypanosomes species or subspecies, especially $T$. $b$. brucei from $T$. $b$. gambiense which are morphologically identical. Animals tested positive for trypanosome infections only by PCR were probably carriers of trypanosomes presenting low parasitemia below the detection threshold of CTC. Finding some animals with T. b. gambiense infections that were negative for the parasitological tests is not surprising because experimental studies have shown that such infections in animals are generally characterized by low parasitemia [44].

The identification of trypanosomes of the subgenus Trypanozoon in pigs, goats, sheep and dogs of Chadian HAT foci is in agreement with results reported in HAT foci of West and Central Africa [20, 41, 42, 51, 53]. Between animal species, the present study revealed no significant difference in the infection rate of trypanosomes of the subgenus Trypanozoon, while significant differences were reported in Cameroonian HAT foci $[38,39]$. Such differences could be explained by the livestock breeding system that differs between HAT foci of different countries or the low power of the present study. In Chadian HAT foci, most domestic animals move freely and share the same biotopes, while in Cameroon, pigs are most often kept in pigsties and therefore, are not exposed to the same level of tsetse bites as other animal species. The significant difference observed between HAT foci for the infection rates of trypanosomes of the subgenus Trypanozoon is in line with results of other Central African countries and suggests that the transmission patterns could vary according to HAT foci [41].

Previous entomological data reporting Glossina tachinoides, G. fuscipes fuscipes and G. morsitans submorsitans in HAT foci of Chad [46] suggest that among the 150 animals found with trypanosomes of the subgenus Trypanozoon, some may be infected by trypanosomes belonging to the $T$. brucei species complex. This hypothesis is confirmed by the detection of $T . b$. gambiense in animals of the three HAT foci. The identification of natural infections of T. b. gambiense in pigs, sheep, goats and dogs confirm results obtained in some West and Central African HAT foci [8, 9, 16, 17, 28, 40-43, 50, 51, 56]. Moreover, experimental studies have demonstrated that all 
animal species found with $T . b$. gambiense can maintain this parasite for several months with the possibility of completing its cyclical transmission [35]. These animals can therefore be considered potential hosts for T. $b$. gambiense in HAT foci of Chad.

Our results showing no significant difference in the infection rates of $T$. b. gambiense between animal species and HAT foci are not in agreement with those reported in Cameroon [41]. In Cameroonian foci, the infection rates of T. b. gambiense varied significantly from zero in dogs to $6.7 \%$ in sheep, and from zero in the HAT focus of Doume to $4.8 \%$ at Campo [41]. The discrepancy observed suggests that the transmission patterns of T. b. gambiense may vary between HAT foci or animal species. This variation could be linked to the fauna composition, the density and tsetse species, the behavior of vertebrate hosts and the nutritional preference of tsetse in each HAT focus or the study design. Located in the southern part of Chad, the three HAT foci have more likely the same fauna composition as well as similar biotopes. Living and moving together in similar environmental conditions, all animal species that were investigated in the present study may be subjected to the same level of tsetse bites. In such a context, the transmission pattern of $T$. $b$. gambiense could be similar in Chadian HAT foci although additional investigations are required to confirm this hypothesis. In Cameroonian HAT foci, the transmission pattern may vary because the fauna composition and the nutritional preference of tsetse flies vary according HAT foci [13, 40, 41, 52].

The discrepancies observed in the infection rates of $T . b$. gambiense between animal species and HAT foci of Cameroon and Chad could be also explained by the actors involved in the transmission cycle of $T . b$. gambiense in each epidemiological setting. In some villages of Mandoul and Maro HAT foci where infections due to T. $b$. gambiense were reported in animals but not in humans, the transmission cycle may involve tsetse and domestic animals. This type of transmission cycle has already been reported in some Central African HAT foci [8-10, 52]. The transmission cycle could be different in other villages where $T$. $b$. gambiense were reported in both humans and domestic animals. This cycle may involve humans, animals, and tsetse flies. Such mixed transmission cycles have been reported in Cameroonian HAT foci [52]. Our study shows that investigations on animal reservoirs in different epidemiological settings are of great value for understanding the transmission of T. b. gambiense. Our results indicate that reaching the total interruption of HAT transmission by 2030, as indicated in the WHO Road Map, requires an understanding of the frequency at which $T . b$. gambiense could be transmitted from animal reservoirs to humans.

Taking together results of $T . b$. gambiense infections in animals with those deriving from medical surveys performed the same year in humans of the same HAT foci (National sleeping sickness control program, 2018, unpublished data), it appeared that 18 animals were found with T. b. gambiense infections and 12 new HAT cases were detected. Although a direct comparison cannot be done between infections in humans and animals due to variations in the population size and host species, the spatial distribution of $T$. b. gambiense infections in humans and animals shows that, in all villages where HAT cases have been reported, domestic animals were found with $T$. b. gambiense infections. The number of villages in which animals were found with $T$. $b$. gambiense is higher than that reporting such infections in humans. In the Mandoul HAT focus where 12 animals of 10 villages were found with $T . b$. gambiense infections, HAT cases were reported in only five villages. However, in the HAT focus of Moissala, T. b. gambiense were reported in humans and animals of the same villages. These results show that the epidemiological situation of HAT and especially the animal reservoir and the transmission of $T . b$. gambiense may vary between HAT foci. The concomitant presence of $T . b$. gambiense infections in animals and humans of the same village highlights a probable link between infections in humans and animals. It suggests a possible transmission of T. b. gambiense between these hosts and probably an epidemiological connection between infections of $T . b$. gambiense in humans and animals. Clearly, the domestic animals found with T. b. gambiense can move freely in and around villages. Sharing the same environment with humans, tsetse flies can take their blood meals either on humans or domestic animals and therefore, can become infected or ensure the transmission to both humans and animals. For villages reporting T. b. gambiense infections in animals and no HAT case in humans, some hypotheses can be formulated to explain these infections. Considering inhabitants' movement within and between villages surrounding each HAT focus, it is likely that tsetse can become infected by feeding on HAT patients who visit villages where no HAT case has been reported. If $T . b$. gambiense completes its development cycle, infected flies can ensure the transmission to animals during blood meals. Some animals with T. b. gambiense infections could acquire these infections in HAT endemic villages during their movements. Although the movement of tsetse flies is generally limited in space, we cannot rule out the fact that infected flies could migrate from HAT endemic villages to those where no HAT cases have been reported.

In both humans and animals, parasite transmission can be performed by the same vector and can occur in the same environment. Control operations could therefore have an impact on the infection rates of T. b. gambiense in humans and animals. The medical surveys regularly undertaken in the three HAT foci have continuously reduced the number of human infections. Before and during our sampling period, no control strategy for animal African trypanosomiases was undertaken in these HAT foci. The high infection rate reported in animals could result from infections dating back several months or years because most animals found with T. b. gambiense can maintain this parasite for many years [32, 33, 45, 49]. In such infected animals, $T$. $b$. gambiense conserves its biochemical and human infectivity markers for more than one year, and therefore, could maintain the parasite and ensure its transmission to humans and animals [34]. The cyclical transmission of T. b. gambiense that has been demonstrated between tsetse, goats, sheep, pigs, dog and various wild animals is another argument highlighting the epidemiological role of animal reservoirs in the gambienseHAT [15, 25, 30, 31, 48, 57]. In some contexts, animals found with $T$. $b$. gambiense can maintain these latent infections for several years. In consequence, the persistent of "residual foci" and the sporadic resurgence of some HAT foci may result from the existence of latent infections in domestic or wild animal 
reservoirs known as source of blood meals for tsetse [11, 22, 23].

In the three HAT foci, sampling was not performed at the same period. This may have potential impacts on trypanosome infections given the fact that seasonal variations could influence the activity of tsetse flies. Moreover, entomological data on the population dynamics and nutritional behavior of tsetse flies as well as trypanosome infection rates in these flies have not been taken into consideration. Such data could yield additional value to understand the transmission dynamics of trypanosomes between tsetse and vertebrate hosts.

\section{Conclusion}

This study showed that pigs, dogs, sheep and goats are carriers of natural infections of $T . b$. gambiense in Chadian HAT foci. These animals can be considered as potential reservoir hosts of T. $b$. gambiense in Chad. The identification of $T . b$. gambiense in all animal species of all HAT foci suggests that these animals should be considered in the design of control strategies for HAT. As these animals could play a role in the maintenance and resurgence of HAT, further investigations aiming to decrypt their role in each epidemiological setting are important to achieve the WHO goal of zero transmission to humans by 2030 .

\section{Supplementary material}

Supplementary material is available at https://www.parasitejournal.org/10.1051/parasite/2020061/olm

Table S1. Trypanosome infections according to villages of each HAT focus

Acknowledgements. We gratefully acknowledge the financial support of the "Organisation de Coordination pour la lutte contre les Endémies en Afrique Centrale (OCEAC)", the "Communauté Economique des Etats de l'Afrique Centrale (CEMAC)", the German Federal Ministry for Economic Cooperation and Development (BMZ) through the German Development Bank (KfW), and the Molecular Parasitology and Entomology unit of the faculty of science of the university of Dschang.

\section{Funding}

This study was funded through a fellowship offered by the Organisation de Coordination pour la lutte contre les Endémies en Afrique Centrale (OCEAC), based on the financial cooperation between the CEMAC and the German Federal Ministry for Economic Cooperation and Development (BMZ) and administered by the Kreditanstalt für Wiederaufbau (KfW)

\section{Competing interests}

The authors declare that they have no conflict of interest.

\section{References}

1. Biéler S, Waltenberger H, Barrett MP, McCulloch R, Mottram JC, Carrington M, Schwaeble W, McKerrow J, Phillips MA, Michels PA, Büscher P, Sanchez JC, Bishop R, Robinson DR, Bangs J, Ferguson M, Nerima B, Albertini A, Michel G, Radwandska M, Ndung'u JM. 2016. Evaluation of antigens for development of a serological test for human African trypanosomiasis. Plos One, 11, e0168074.

2. Bisser S, Lumbala C, Nguertoum E, Kande V, Flevaud L, Vatunga G, Boelaer M, Büscher P, Josenando T, Bessell PR, Biéler S, Ndung'u JM. 2016. Sensitivity and specificity of a prototype rapid diagnostic test for the detection of Trypanosoma brucei gambiense infection: a multi-centric prospective study. Plos Neglected Tropical Diseases, 10, e0004608.

3. Bureau P. 1996. Historique et évolution de la maladie du sommeil au Tchad. Bulletin de Liaison et de Documentation OCEAC, 29, 90-98.

4. Büscher P, Mertens P, Leclipteux T, Gilleman Q, Jacquet D, Mumba-Ngoyi D, Pyana PP, Boelaert M, Lejon V. 2014. Sensitivity and specificity of HAT Sero-K-SeT, a rapid diagnostic test for serodiagnosis of sleeping sickness caused by Trypanosoma brucei gambiense: a case-control study. Lancet Global Health, 2, e359-e363.

5. Buscher P, Cecchi G, Jamonneau V, Priotto G. 2017. Human African trypanosomiasis. Lancet, 390, 2397-2409.

6. Büscher P, Bart JM, Boelaert M, Bucheton B, Cecchi G, Chitnis N, Courtin D, Figueiredo LM, Franco JR, Grébaut P, Hasker E, Ilboudo H, Jamonneau V, Koffi M, Lejon V, MacLeod A, Masumu J, Matovu E, Mattioli R, Noyes H, Picado A, Rock KS, Rotureau B, Simo G, Thévenon S, Trindade S, Truc P, VanReet N. 2018. Do cryptic reservoirs threaten gambiense-sleeping sickness elimination? Trends in Parasitology, 34, 197-207.

7. Büscher P, Gonzatti MI, Hébert L, Inoue N, Pascucci I, Schnaufer A, Suganuma K, Touratier L, Van Reet N. 2019. Equine trypanosomosis: enigmas and diagnostic challenges. Parasites \& Vectors, 12, 234.

8. Cordon-Obras C, Berzosa P, Ndong-Mabale N, Bobuakasi L, Buatiche JN, Ndongo-Asumu P, Cano AB. 2009. Trypanosoma brucei gambiense in domestic livestock of Kogo and Mbini foci (Equatorial Guinea). Tropical Medicine and International Health, 14, 535-541.

9. Cordon-Obras C, García-Estébanez C, Ndong-Mabale N, Abaga S, Ndongo-Asumu P, Benito A, Cano J. 2010. Screening of Trypanosoma brucei gambiense in domestic livestock and tsetse flies from an insular endemic focus (Luba, Equatorial Guinea). Plos Neglected Tropical Diseases, 4, e704.

10. Cordon-Obras C, Rodriguez YF, Fernandez-Martinez A, Cano J, Ndong-Mabale N, Ncogo-Ada P, Ndongo-Asumu P, Aparicio P, Navarro M, Benito A, Bart JM. 2015. Molecular evidence of a Trypanosoma brucei gambiense sylvatic cycle in the human african trypanosomiasis foci of Equatorial Guinea. Frontiers in Microbiology, 6, 765.

11. Denecke K. 1941. Menschenpathogene Trypanosomemdes Hundes auf FernandoPoo. Ein Beitrag zur Epidemiologie der Schlafkrankheit. Archiv für Hygiene und Bakteriologie, 126, 38-42.

12. Dumas R. 1980. Contribution à l'étude des petits ruminants du Tchad. Revue d'Élevage et de Médecine Vétérinaire des Pays tropicaux, 33, 215-233.

13. Farikou O, Njiokou F, Simo G, Asonganyi T, Cuny G, Geiger A. 2010. Tsetse fly blood meal modification and trypanosome identification in two sleeping sickness foci in the forest of southern Cameroon. Acta Tropica, 116, 81-88. 
14. Franco JR, Cecchi G, Priotto G, Paone M, Diarra A, Grout L, Simarro PP, Zhao W, Argaw D. 2018. Monitoring the elimination of human African trypanosomiasis: update to 2016. Plos Neglected Tropical Diseases, 12, e0006890.

15. Franco JR, Cecchi G, Priotto G, Paone M, Diarra A, Grout L, Simarro PP, Zhao W, Argaw D. 2020. Monitoring the elimination of human African trypanosomiasis at continental and country level: update to 2018. Plos Neglected Tropical Diseases, 14, e0008261.

16. Gibson WC, Mehlitz D, Lanham SM, Godfrey DG. 1978. The identification of Trypanosoma brucei gambiense in Liberian pigs and dogs by isoenzymes and by resistance to human plasma. Tropical Medicine and Parasitology, 29, 335-345.

17. Herder S, Simo G, Nkinin SW, Njiokou F. 2002. Identification of trypanosomes in wild animals from Southern Cameroon using the polymerase chain reaction (PCR). Parasite, 9, 345349.

18. Holland WG, Thanh NG, Do TT, Sangmeneeddet S, Goddeeris B, Vercruysse J. 2005. Evaluation of diagnostic tests for Trypanosoma evansi in experimentally infected pigs and subsequent use in field surveys in North Vietnam and Thailand. Tropical Animal Health and Production, 37, 457-467.

19. Jackson AP, Sanders M, Berry A, McQuillan J, Aslett MA, Quail MA, Chukualim B, Capewell P, MacLeod A, Melville SE, Gibson W, Barry JD, Berriman M, Hertz-Fowler C. 2010. The genome sequence of Trypanosoma brucei gambiense, causative agent of chronic human African trypanosomiasis. Plos Neglected Tropical Diseases, 4, e658.

20. Jamonneau V, Ravel S, Koffi M, Kaba D, Zeze DG, Ndri L, Sane B, Coulibaly B, Cuny G, Solano P. 2004. Mixed infections of trypanosomes in tsetse and pigs and their epidemiological significance in a sleeping sickness focus of Côte d'Ivoire. Parasitology, 129, 693-702.

21. Jamonneau V, Camara O, Ilboudo H, Peylhard M, Koffi M, Sakande H, N'Dri L, Sanou D, Dama E, Camara M, Lejon V. 2015. Accuracy of individual rapid tests for serodiagnosis of gambiense sleeping sickness in West Africa. Plos Neglected Tropical Diseases, 9, e0003480.

22. Jannssens PG, Wery M, van Meirvenne N. 1984. Current knowledge and prospects in the field of African trypanosomiasis, in Medizin in Entwicklungsländer. Verlag Peter Lang: Frankfurt/M, Bd 16. p. 21-37. ISSN 0721-3247, ISBN 3-82045427-6.

23. Karshima SN, Lawal IA, Bata SI, Barde IJ, Adamu PV, Salihu A, Dross PM, Obalisa A. 2016. Animal reservoirs of Trypanosoma brucei gambiense around the old Gboko sleeping sickness focus in Nigeria. Journal of Parasitology and Vector Biology, 8, 47-54.

24. Koffi M, Solano P, Denizot M, Courtin D, Garcia A, Lejon V, Büscher P, Cuny G, Jamonneau V. 2006. Aparasitemic serological suspects in Trypanosoma brucei gambiense human African trypanosomiasis: a potential human reservoir of parasites? Acta Tropica, 98, 183-188.

25. Laveissière C, Couret D, Staak C, Hervouet JP. 1985. Glossina palpalis et ses hПtes en secteur forestier de CØte d'Ivoire. Relation avec l'épidémiologie de la trypanosomiase humaine. Cahier O.R.S.T.O.M. Série d'Entomologie Médicale et Parasitologie, 23, 297-303.

26. Magrin G. 2001. Le sud du Tchad en mutation: des champs de coton aux sirènes de l'or noir. Montpellier, France: Cirad.

27. Mahamat MH, Peka M, Rayaisse J-B, Rock KS, Toko MA, Darnas J, Brahim GM, Alkatib AB, Yoni W, Tirados I, Courtin F, Brand SPC, Nersy C, Alfaroukh IO, Torr SJ, Lehane MJ, Solano P. 2017. Adding tsetse control to medical activities contributes to decreasing transmission of sleeping sickness in the Mandoul focus (Chad). Plos Neglected Tropical Diseases, 11, e0005792.

28. Makumyaviri A, Mehlitz D, Kageruka P, Kazyumba GL, Molisho D. 1989. Animal reservoir hosts of Trypanosoma brucei gambiense in Zaire: trypanosome infections in two foci in Bas-Zaire. Tropical Medicine and Parasitology, 40, 258-262.

29. Matovu E, Kitibwa A, Picado A, Biéler S, Bessell PR, Ndungu JM. 2017. Serological tests for gambiense human African trypanosomiasis detect antibodies in cattle. Parasites \& Vectors, $10,546$.

30. Mehlitz D. 1977. The behaviour in the blood inoculation infectivity test of four Trypanozoon strains isolated from pigs in Liberia. Transaction of the Royal Society of Tropical Medicine and Hygiene, 71, 86.

31. Mehlitz D. 1982. Trypanosomes in African wild animals, in Perspectives in Trypanosomiasis Research, Baker JR, Editor. Research Study Press: Chicester, IN. p. 25-35.

32. Mehlitz D. 1985. Epidemiological studies on the significance of animal reservoir hosts of Trypanosoma brucei gambiense. Final Report to the UNDP/WHO/World Bank Special Programme on African Trypanosmiases. Project No. 820021 29.01.1985.

33. Mehlitz D. 1986. Le réservoir animal de la maladie du sommeil à Trypanosoma brucei gambiense, in Études et Synthèses de l'IEMVT n. 18. CIRAD-IEMVT: Maisons-Alfort. p. 156. ISBN 2-85985-127-5.

34. Mehlitz D, Sachs R, Zillmann U. 1983. Further results on the cyclical transmission of human derived Trypanosoma brucei gambiense to antelopes and a goat. Annual Report of the Liberia Research Unit (LRU) of the Tropical Institute Hamburg for the years 1982 and 1983. p. 2-3.

35. Mehlitz D, Molyneux DH. 2019. The elimination of Trypanosoma brucei gambiense? Challenges of reservoir hosts and transmission cycles: expect the unexpected. Parasite Epidemiology and Control, 6, e00113.

36. Molyneux DH. 1973. Isolation of Trypanosoma (Trypanozoon) brucei gambiense in rabbits by the intratesticular inoculation technique. Annal of Tropical Medicine and Parasitology, 67, 391-397.

37. Morrison LJ, Tait A, McCormack G, Sweeney L, Black A, Truc P, Likeufack AC, Turner MC, MacLeod A. 2008. Trypanosoma brucei gambiense type 1 populations from human patients are clonal and display geographical genetic differentiation. Infection, Genetic, and Evolution, 8, 847-854.

38. Moser DR, Cook GA, Ochs DE, Bailey CP, Mckane MR, Donelson JE. 1989. Detection of Trypanosoma congolense and Trypanosma brueci subspecies by DNA amplification using the polymerase chain reaction. Parasitology, 99, 57-66.

39. Ndoutamia G, Brahim A, Nadjindoroum P, Moudaidandi G, Diimgang G, Loubadjim R. 2000. Sensibilité des chèvres Kirdimi et Sahéliennes du Tchad à la trypanosomose à Trypanosoma congolense. Revue d'Élevage et de Médecine Vétérinaire des Pays Tropicaux, 53, 9-15.

40. Njiokou F, Laveissière C, Simo G, Grébaut P, Cuny G, Herder S. 2006. Wild fauna as probable animal reservoir for Trypanosoma brucei gambiense in Cameroon. Infection, Genetics and Evolution, 6, 147-153.

41. Njiokou F, Nimpaye H, Simo G, Njitchouang GR, Asonganyi T, Cuny G, Herder S. 2010. Domestic animals as potential reservoir hosts of Trypanosoma brucei gambiense in sleeping sickness foci in Cameroon. Parasite, 17, 61-66.

42. Nkinin SW, Njiokou F, Penchenier L, Grebaut P, Simo G, Herder S. 2002. Characterization of Trypanosoma brucei s.l. subspecies by isoenzymes in domestic pigs from the Fontem sleeping sickness focus of Cameroon. Acta Tropica, 81, 225232. 
43. Noireau F, Gouteux JP, Frezil JL. 1986. Sensibilité du test d'agglutination sur carte (TESTRYP CATT) dans les infections porcines à Trypanosoma (nannomonas) congolense en République Populaire du Congo. Annales de la Société Belge de Médecine Tropicale, 66, 63-68.

44. Noireau F, Paindavoine P, Lemesre JL, Toudic A, Pays E, Gouteux JP, Steinert M, Frezil JL. 1989. The epidemiological importance of the animal reservoir of Trypanosoma brucei gambiense in the Congo: characterisation of the T. brucei complex. Tropical Medicine and Parasitology, 40, 9-11.

45. Paindavoine P, Pays E, Laurent M, Geltemeyer Y, Le Ray D, Mehlitz D, Steinert M. 1986. The use of DNA hybridization and numerical taxonomy in determining relationship between Trypanosoma brucei stocks and subspecies. Parasitology, 92, 3150.

46. Peka M, Kohagne TL, Ndjeleje N, Louis FJ, Hassane MH. 2014. Transmission concomitante de Trypanosomose humaine et animale: le foyer du Mandoul au Tchad. Revue d'Élevage et de Médecine Vétérinaire des Pays Tropicaux, 67, 5-12.

47. Radwanska M, Claes F, Magez S. 2002. Novel primer sequences for polymerase chain reaction-based detection of Trypanosoma brucei gambiense. American Journal of Tropical Medicine and Hygiene, 67, 289-295.

48. Schöning B. 1989. Der Hund als Reservoir für Trypanosoma (Trypanozoon) brucei gambiense: Vergleichende Untersuchungen zur Empfänglichkeit für T. b. gambiense Dutton, 1902 und T. b. brucei Plimmer \& Bradford, 1899 und zum Infektionsverlauf bei einer europäischen und einer westafrikanischen Hunderasse. Dissertation Thesis (English summary). Germany: Faculty of Veterinary Medicine, Free University Berlin. Journal No. 1481.

49. Schütt ID, Mehlitz D. 1981. On the persistence of human serum resistance and isoenzyme patterns of Trypanozoon in experimentally infected pigs. Acta Tropica, 38, 367-373.

50. Scott CM, Frezil JL, Toudic A, Godfrey DG. 1983. The sheep as a potential reservoir of human trypanosomiasis in the Republic of the Congo. Transaction of the Royal Society of Tropical Medicine and Hygiene, 77, 397-401.

51. Simo G, Asonganyi T, Nkinin SW, Njiokou F, Herder S. 2006. High prevalence of Trypanosoma brucei gambiense group 1 in pigs from the Fontem sleeping sickness focus in Cameroon. Veterinary Parasitology, 139, 57-66.

52. Simo G, Njiokou F, Mbida Mbida JA, Njitchouang GR, Herder S, Asonganyi T, Cuny G. 2008. Tsetse fly host preference from sleeping sickness foci in Cameroon: epidemiological implications. Infection, Genetics and Evolution, 8, 34-39.

53. Simo G, Njitchouang GR, Njiokou F, Cuny G, Asonganyi T. 2012. Genetic characterization of Trypanosoma brucei circulating in domestic animals of the Fontem sleeping sickness of Cameroon. Microbes and Infections, 14, 65165-65168.

54. Sistrom M, Evans B, Benoit J, Balmer O, Aksoy S, Caccone A. 2016. De novo genome assembly shows genome wide similarity between Trypanosoma brucei brucei and Trypanosoma brucei rhodesiense. Plos One, 11, e0147660.

55. Sternberg JM, Gierlinski M, Bieler S, Ferguson MAJ, Ndungu JM. 2014. Evaluation of the diagnostic accuracy of prototype rapid tests for human African trypanosomiasis. Plos Neglected Tropical Diseases, 8, e3373.

56. Umeakuana PU, Gibson W, Ezeokonkwo RC, Anene BM. 2019. Identification of Trypanosoma brucei gambiense in naturally infected dogs in Nigeria. Parasites \& Vectors, 12, 420.

57. Van Hoof LM. 1947. Observations on trypanosomiasis in the Belgian Congo. Transaction of the Royal Society of Tropical Medicine and Hygiene, 40, 728-761.

58. Vourchakbé J, Tiofack AAZ, Mbida M, Simo G. 2020. Trypanosome infections in naturally infected horses and donkeys of three active sleeping sickness foci in the south of Chad. Parasites \& Vectors, 13, 323.

59. WHO. 2020. Report of the third WHO stakeholders meeting on gambiense human African trypanosomiasis elimination. Geneva, Switzerland

60. Woo PTK. 1970. The haematocrit centrifuge technique for the diagnosis of African trypanosomiasis. Acta Tropica, 27, 384386.

61. Zweygarth E, Sabwa C, Rottcher D. 1984. Serodiagnosis of trypanosomiasis in dromedary camels using a card agglutination test set $\left(\right.$ Testryp $^{\circledR}$ CATT). Annales de la Société BeIge de Médecine Tropicale, 64, 309-313.

Cite this article as: Vourchakbé J, Tiofack ZAA, Kante TS, Mpoame M \& Simo G. 2020. Molecular identification of Trypanosoma brucei gambiensein naturally infected pigs, dogs and small ruminants confirms domestic animals as potential reservoirs for sleeping sicknessin Chad. Parasite 27, 63.

Reviews, articles and short notes may be submitted. Fields include, but are not limited to: general, medical and veterinary parasitology; morphology, including ultrastructure; parasite systematics, including entomology, acarology, helminthology and protistology, and molecular analyses; molecular biology and biochemistry; immunology of parasitic diseases; host-parasite relationships; ecology and life history of parasites; epidemiology; therapeutics; new diagnostic tools.

All papers in Parasite are published in English. Manuscripts should have a broad interest and must not have been published or submitted elsewhere. No limit is imposed on the length of manuscripts.

Parasite (open-access) continues Parasite (print and online editions, 1994-2012) and Annales de Parasitologie Humaine et Comparée (1923-1993) and is the official journal of the Société Française de Parasitologie. 